\title{
Analysis of pesticides in lanolin by gel permeation chromatography and gas chromatography
}

\author{
M. López-Mesas ${ }^{1 *}$, M. Crespi ${ }^{1}$, J. Brach ${ }^{2}$ and J.P. Mullender ${ }^{2}$ \\ ${ }^{1}$ Laboratorio de Control de la Contaminación Ambiental. Instituto de Investigación Téxtil y Cooperación \\ Industrial (INTEXTER). Colón 15, 08222 Terrassa, Spain \\ ${ }^{2}$ Centre de Recherche et de Service CELABOR, Avenue du Parc 38, 4650 Herve, Belgium
}

\begin{abstract}
In this paper the efficiency of a method for the separation and identification of pesticides in lanolin is presented. Theses pesticides belong to the organophosphorous and synthetic pyrethroids families. After the gel permeation chromatography, pesticides are separated from lanolin into two fractions corresponding to the two families, which simplify subsequent analysis by gas chromatography.
\end{abstract}

Keywords. Gas Chromatography with Electron Capture Detector (GC-ECD) - Gel Permeation Chromatography (GPC) lanolin - organophosphorous pesticides - synthetic pyrethroids pesticides.

\section{Introduction}

The product resulting by cleaning up the grease secreted by sebaceous glands of sheep is known as lanolin or wool grease. Due to its high compatibility with human skin oils, it is widely used as a moisturizer in cosmetics [1] and for pharmaceutical preparations [2,3]. Generally it is obtained from wool scouring, after centrifugation of the liquor phase. Pesticides are used as sheep antiparasites or for wool storage, and they have to be subsequently eliminated from wool together with lanolin. When lanolin is used for human consumer product, pesticides should be detected and analysed.

Pesticides that can be found in lanolin are those allowed for use in sheep (synthetic pyrethroid and organophosphorous pesticides) [4]. The presence of organochloro compounds can be due to the ingestion of grass from the pastures treated with them, contaminated soil and illegal use.

Lanolin consist of complex mixtures of long chains of fatty acids and esters in which pesticides remain strongly retained due to their lipophilic character [5]. Characteristics of these lipids include polar groups (H bonds), high content in hydrocarbon, high molecular weight (between 600-1500) and low volatility, which can be used for the separation of pesticides.

When pesticides from a sample containing a high proportion of fat are analysed, a three steps procedure is needed [6]: an extraction stage which allows the separation of analytes from the fat matrix, a clean up stage which eliminates the interfering components, and finally a separation, identification, and quantification of the pesticides, which can be made by gas-liquid chromatography with electron capture detector (GLC-ECD) [7].

The two first steps are considered to be the most critical, since the achievement of the appropiate fractions needed in further analysis, depends on them [8].

In the clean-up step, the most universally system applied is gel permeation chromatography (GPC) [9-11]. Polymers used in the GPC columns don't involve losses of pesticides by adsorption. Lipids, due to their higher molecular weight, elute first from these columns followed by pesticides.

In this paper, a clean-up procedure and a detection method are presented using a pesticide-spiked lanolin.

\section{Experimental part}

\section{Material and procedure}

\section{Gas chromatograph}

A gas chromatograph, model Hewlett Packard HP6890, fitted with an automatic injector (Series Injector) was used. The column was a $30 \mathrm{~m}(320 \mu \mathrm{m}$ i.d., film thickness $0.25 \mu \mathrm{m}) \mathrm{HP}-5$, constituted by a phase consisting of $5 \%$ Diphenyl-95 \%-dimethylsiloxane. Helium was used as the carrier gas. Detection was made by ECD, model HP6890. Data were collected and statistically treated by Chemstation HP Software. 


\section{Original articles}

\section{Gas chromatography determination}

Initial oven temperature $\left(100{ }^{\circ} \mathrm{C}\right)$ was increased up to $200{ }^{\circ} \mathrm{C}$ at $35^{\circ} \mathrm{C} / \mathrm{min}$, then up to $210^{\circ} \mathrm{C}$ at $3{ }^{\circ} \mathrm{C} / \mathrm{min}$ where was holded for 1 minute and finally up to $295^{\circ} \mathrm{C}$ at $4{ }^{\circ} \mathrm{C} / \mathrm{min}$. Injector and detector were setted at $250{ }^{\circ} \mathrm{C}$ and $240{ }^{\circ} \mathrm{C}$ respectively. Inlet was programmed in pulsed splitless mode with a purge flow of $25 \mathrm{~mL} / \mathrm{min}$.

Pesticides were individually injected in the method described above, to identify the retention time of each one.

\section{Gel permeation chromatography}

An equipment fitted with an HPLC Varian Vista 5500 LC pump, UV-Visible Varian 634 Detector and a Varian Star Chromatography Software integrator was employed. Injector was model 7000 Stream Switching Valve with a $2 \mathrm{~mL}$ sample loop. Two chromatographic columns were used, made of transparent glass (450 $\mathrm{mm} \times 15 \mathrm{~mm}$ ID), and manually filled with the polymer BIO-BEADS S-X3 (Bio-Rad ref. 1522750). All connections were made in PTFE pipe 1/16", $0.8 \mathrm{mmID}$ and $1 / 8^{\prime \prime}, 1.5 \mathrm{~mm}$ ID.

\section{Gel permeation chromatography determination}

Before initiating the clean-up study, the homogeneity of the paking of the gel permeation chromatography columns was checked by injecting a phtalate sample. The retention time and the area of the peak were compared to the standard injected when the columns were just packed.

Two $\mathrm{mL}$ of sample were injected for the successive analyses. The solvent used for the elution of the analytes was dichloromethane at $4 \mathrm{~mL} / \mathrm{min}$ flow. Detection was set at $254 \mathrm{~nm}$.

\section{Reagents}

Nine pesticides were selected, five of them belonging to the synthetic pyrethroids (cyhalothrin, cypermethrin, deltamethrin, fenvalerate and tetramethrin) and four organophosphorous (carbophenothion, chlorpyriphos-methyl, diazinon and propetamphos). All of them were over $99 \%$ pure. Lanolin was pesticide free degree from Westbrook Lanolin, Verviers, Belgium. All solvents used were Pestiscan grade from Lab-Scan Analytical Science. Injections were always made in duplicate (otherwise it's indicated).

\section{Results and discussion}

\section{Gel permeation chromatography}

\section{Analysis of lanolin elution}

Lanolin solutions at $2 \%$ in dichloromethane was prepared. After injection, a first peak appeared at $11.5 \mathrm{~min}$, a main signal was observed at $16.5 \mathrm{~min}$ and two smaller peaks at 21.3 and $22.8 \mathrm{~min}$.
$2 \mathrm{~mL}$ of a lanolin solution at $25 \%$ was injected and the fractions eluted were collected every two minutes from minute 10 until minute 26, in calibrated vials. Solvent was evaporated to dryness under nitrogen atmosphere and the recovery of the grease was calculated. As can be seen (Fig. 1), the grease reaches its maximum in the time interval 16-18 minutes while at 22 min a small percentage still remains to elute.

\section{Analysis of elution of the mixture of pesticides}

A $5 \mathrm{mg} / \mathrm{L}$ standard mixture of pesticides was injected in the gel permeation chromatography under the same conditions lanolin was injected. One peak of weak intensity, was observed between minutes 20-25. Eluted fractions were collected from the column every two minutes between minutes 16 and 38, evaporated to dryness, reconstituted in $5 \mathrm{~mL}$ of cyclohexane and injected in the chromatograph.

From the results, recovery of each fraction versus the elution time was presented (Fig. 2). Two elution groups can be differentiated: between minutes 19 and 22 synthetic pyrethroid pesticides were eluted, while the organophosphorous were eluted between 22 and 28 minutes.

Recovery percentages higher than $85 \%$ for each pesticide were obtained (Tab. I).

\section{Analysis of the elution of a lanolin-pesticide sample}

$2 \mathrm{~mL}$ of a solution $2 \%$ in lanolin, spiked with $5 \mathrm{mg} / \mathrm{L}$ of each of the nine pesticides, was injected in the gel permeation chromatography column. Eluted fractions were taken every five minutes since minute 18 , evaporated to dryness

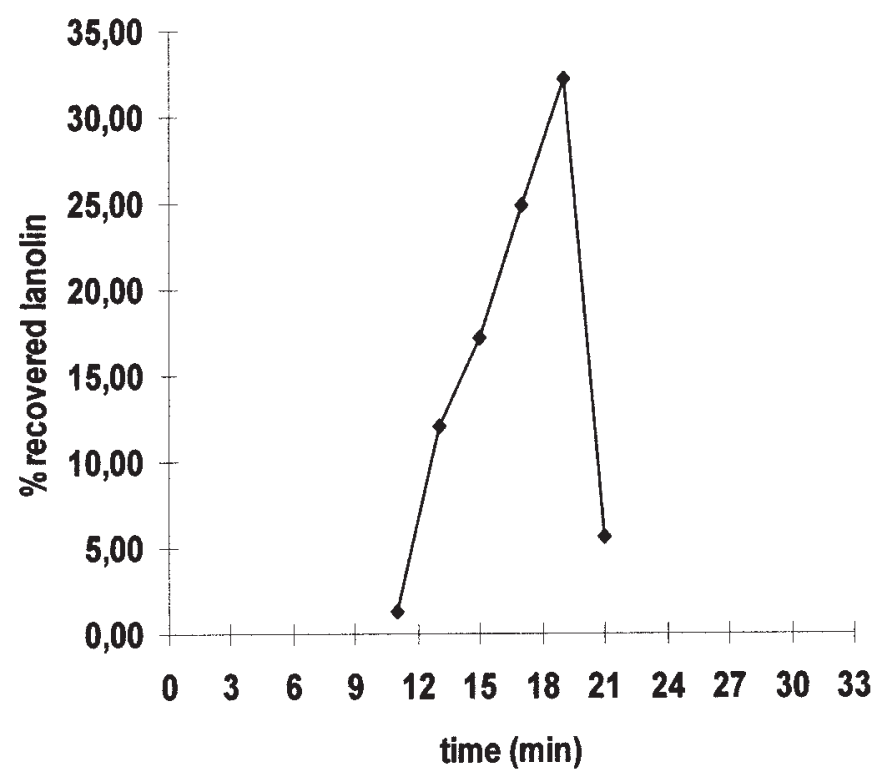

Figure 1. Recovery percentages of lanolin in each fraction collected at the discharge of gel permeation chromatography column. 
Table I. Recovery percentages of the nine pesticides analysed.

\begin{tabular}{lcc}
\hline Pesticide & \% recovery & $S D$ \\
\hline Propetamphos & 97,3 & 0,42 \\
Diazinon & 98,9 & 0,14 \\
Chlorpyrifos-methyl & 92,75 & 0,35 \\
Carbophenothion & 87,15 & 1,20 \\
Tetramethrin & 106,25 & 1,77 \\
Cyhalothrin & 116,25 & 8,84 \\
Cypermethrin & 97,8 & 0,28 \\
Fenvalerate & 100,1 & 1,56 \\
Deltamethrin & 97,55 & 0,64 \\
\hline
\end{tabular}

Table II. Statistical analysis of the Capacity Factor for the nine pesticides.

\begin{tabular}{lcccc}
\hline \multirow{2}{*}{$\begin{array}{l}\text { Pesticide } \\
\text { k } k^{\prime} \text { average }\end{array}$} & S.D. & R.S.D. & $95 \%$ CI \\
\hline Propetamphos & 1.87281 & 0.00043 & 0.02278 & 0.00031 \\
Diazinon & 1.92759 & 0.00048 & 0.02464 & 0.00034 \\
Chlorpyrifos-met & 2.37789 & 0.00043 & 0.0179 & 0.0003 \\
Carbophenothion & 5.0705 & 0.00085 & 0.01677 & 0.00061 \\
Tetramethrin & 6.0507 & 0.00142 & 0.02342 & 0.00101 \\
Cyhalothrin & 6.88809 & 0.00106 & 0.01546 & 0.00076 \\
Cypermethrin & 8.49533 & 0.00101 & 0.01185 & 0.00072 \\
Fenvalerate & 9.20656 & 0.00097 & 0.01055 & 0.00069 \\
Deltamethrin & 9.89721 & 0.00113 & 0.01147 & 0.00081 \\
\hline
\end{tabular}

under nitrogen, and reconstituted in $10 \mathrm{~mL}$ of cyclohexane. Finally, they were injected in the gas chromatograph, and recoveries were calculated.

Chromatograms of these injections don't show a flat base line due to the interference of remaining lanolin, nevertheless peaks could be integrated (Fig. 3). Recovery were higher than $85 \%$, excepted for diazinon.

\section{Assessment of the method}

Some testing is necessary in order to assess if the parameters of the gas chromatography process are adaptable to further applications. The parameters studied in this work were capacity factor, selectivity, repeatability and linearity.

To carry out this analysis, a $0.5 \mathrm{mg} / \mathrm{L}$ standard sample, was injected 10 times and chromatograms were analysed in terms of the parameter studied.

Tables II, III and IV show the values for capacity factor, selectivity and repeteability respectively, obtained for each pesticide.

To find the linearity in the method used, seven standard samples were injected between 0.01 and $5 \mathrm{mg} / \mathrm{L}$. The average of the pesticide areas were calculated and the calibration curve obtained for each component. Table V shows the regression data for each pesticide. The response follows linearity until $2 \mathrm{mg} / \mathrm{L}$ in each case, but diazinon ( $1 \mathrm{mg} / \mathrm{L})$.

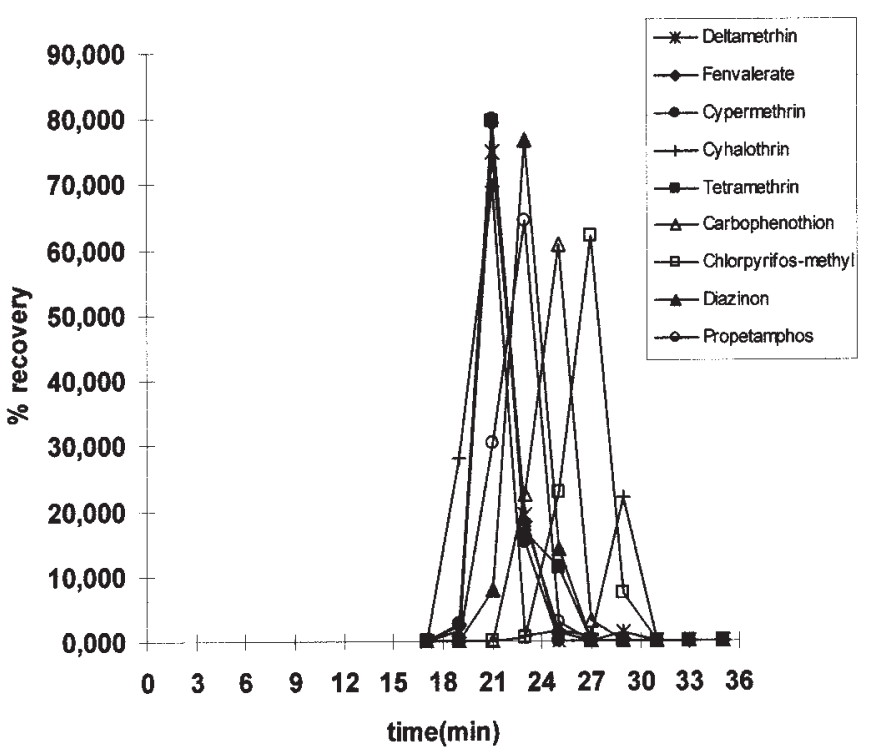

Figure 2. Recovery percentages of the pesticides in each of the different fractions collected at the output of the gel permeation chromatography column.

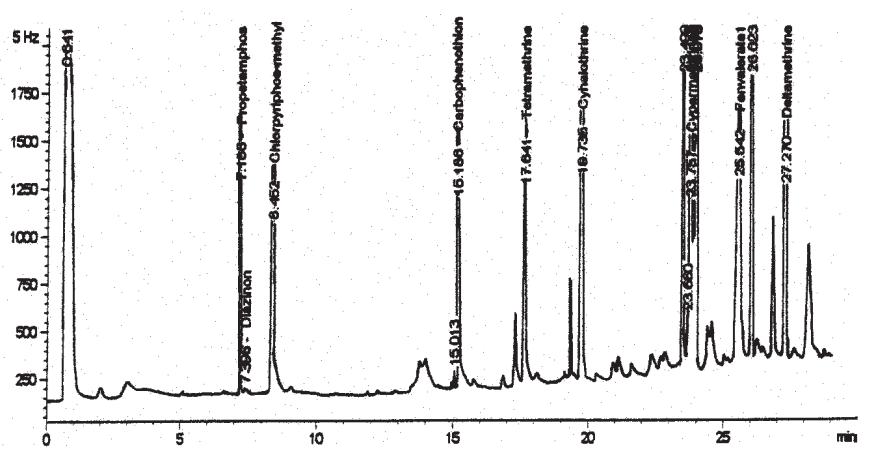

Figure 3. Chromatogram of the injection of the fraction of the pesticides eluted from the gel permeation chromatography column of a lanolin spiked solution.

Table III. Statistical analysis of the Selectivity for the nine pesticides.

\begin{tabular}{lcccc}
\hline \multirow{2}{*}{ Pesticide } & \multicolumn{4}{c}{ Selectivity } \\
& S average & S.D. & R.S.D. & $95 \%$ CI \\
\hline Propetamphos & 1.06084 & 0.05247 & 4.94645 & 0.03754 \\
Diazinon & 1.02925 & 0.00011 & 0.0107 & 0.00008 \\
Chlorpyrifos-met & 1.05919 & 0.00014 & 0.01293 & 0.0001 \\
Carbophenothion & 1.01385 & 0.00009 & 0.00929 & 0.00007 \\
Tetramethrin & 1.02371 & 0.00006 & 0.00576 & 0.00004 \\
Cyhalothrin & 1.02372 & 0.00003 & 0.00325 & 0.00002 \\
Cypermethrin & 1.00484 & 0.00004 & 0.00367 & 0.00003 \\
Fenvalerate & 1.04422 & 0.00005 & 0.00465 & 0.00003 \\
Deltamethrin & 1.01817 & 0.00004 & 0.00431 & 0.00003 \\
\hline
\end{tabular}




\section{Original articles}

Table IV. Statistical analysis of the Retention Time Repeatability for the nine pesticides.

\begin{tabular}{lrrrr}
\hline \multirow{2}{*}{ Pesticide } & \multicolumn{5}{c}{ Retention Time Repeatability } \\
& Average & S.D. & R.S.D. & $95 \%$ CI \\
\hline Propetamphos & 7.1864 & 0.0011 & 0.0148 & 0.00076 \\
Diazinon & 7.3235 & 0.0012 & 0.0162 & 0.00085 \\
Chlorpyrifos-met & 8.4499 & 0.0011 & 0.0126 & 0.00076 \\
Carbophenothion & 15.1856 & 0.0021 & 0.0140 & 0.00152 \\
Tetramethrin & 17.6375 & 0.0035 & 0.0201 & 0.00254 \\
Cyhalothrin & 19.7323 & 0.0027 & 0.0135 & 0.00191 \\
Cypermethrin & 23.7529 & 0.0025 & 0.0106 & 0.0018 \\
Fenvalerate & 25.5320 & 0.0024 & 0.0095 & 0.00174 \\
Deltamethrin & 27.2597 & 0.0028 & 0.0104 & 0.00203 \\
\hline
\end{tabular}

Figure 4 shows the chromatogram obtained when a mixture of the nine pesticides was analysed by the method described above. Pesticides were eluted in 28 minutes.

\section{Conclusions}

Of the analysis of the results of the different parameters studied, the method for the detection of the nine pesticides is valid and surpasses the $95 \%$ reliability test. Excellent recovery for all the pesticides analysed from spiked lanolin was achived.

\section{Acknowledgements}

Ministerio Español de Educación y Cultura is gratefully acknowledged for financial support (AP96 39187769).

\section{References}

1. Diserens, H. J. Assoc. Off. Anal. Chem.1989, 72-6, 991.

2. Goode, T.S. J. Am. Oil Chem. Soc. 1963, 40, 4.

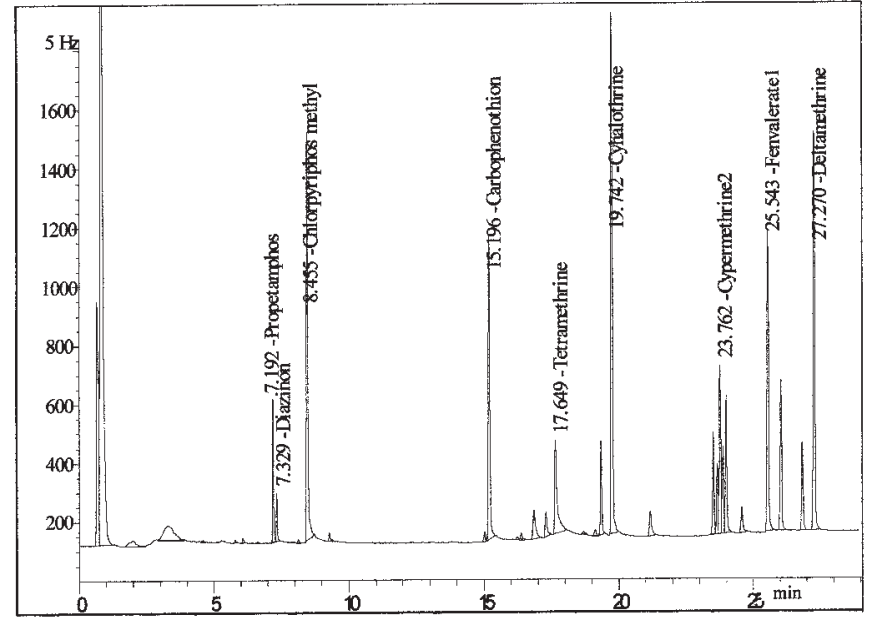

Figure 4. Chromatogram of the injection of a nine pesticides standard sample at $5 \mathrm{ppm}$ each one.

3. Clark, E.W. Chemist 1990, 7, 18 .

4. Shaw, T. Agricultural Chemical in Raw Wool and the Textile Industry, J. IWEM 1994, 8, 287.

5. Mågård, M.Å.; Berg, H.E.B.; Tagesson, V.; Järemo, M.L.G. J. Agric. Food Chem. 1995, 43, 114.

6. Lázaro, R.; Bayarri, S.; Conchello, P.; Ariño, A.; Herrera, A. Grasas y Aceites 1995, 46-1, 35.

7. Jones, F.W. JAOCS 1997, 74-10, 1241.

8. Geene, R.V.; Wimbush, J.M. The Extraction for Chemical Analysis of Pesticide Residues in Wool and Wool Products; IWS.

9. Venant, A.; Borrel, S.; Mallet, J.; Van Neste, E. Analusis 1989, $17-1 / 2,64$

10. Heikes, D.L.; Craun, J.C. J. Agric. Food Chem. 1992, 40, 1586.

11. Armishaw, P.; Millar, R.G. J. of AOAC International 1993, 76$6,1317$.

Table V. Regression data for the calibration of the nine pesticides.

\begin{tabular}{|c|c|c|c|c|c|c|}
\hline PESTICIDE & slope & intercept & $\begin{array}{c}\text { Slope } \\
\text { standard } \\
\text { deviation }\end{array}$ & $\begin{array}{l}\text { Intercept } \\
\text { standard } \\
\text { deviation }\end{array}$ & $\begin{array}{l}\text { Number of } \\
\text { data points }\end{array}$ & $\begin{array}{c}\text { Correlation } \\
\text { coeficient }\end{array}$ \\
\hline Propetamphos & 3525.9 & 107.24 & 97.8 & 91.6 & 7 & 0.9969 \\
\hline Diazinon & 1068.9 & 57.926 & 35.8 & 33.5 & 7 & 0.9955 \\
\hline Chlorpyrifos-met & 20002 & -43.275 & 317.9 & 297.7 & 7 & 0.9990 \\
\hline Carbophenothion & 16077 & -439.42 & 284.6 & 266.5 & 7 & 0.9987 \\
\hline Tetramethrin & 3994.3 & 51.982 & 70.6 & 66.2 & 7 & 0.9988 \\
\hline Cyhalothrin & 26526 & -1050.7 & 427.3 & 400.2 & 7 & 0.9990 \\
\hline Cypermethrin & 7699.1 & -168.23 & 101.2 & 94.8 & 7 & 0.9993 \\
\hline Fenvalerate & 15137 & -476.45 & 212.8 & 199.2 & 7 & 0.9992 \\
\hline Deltamethrin & 19924 & -704.14 & 304.6 & 285.3 & 7 & 0.9991 \\
\hline
\end{tabular}

